Article

\title{
Eco-Friendly Multipurpose Lubricating Greases from Vegetable Residual Oils
}

\section{Ponnekanti Nagendramma * and Prashant Kumar}

Bio Fuels Division, CSIR-Indian Institute of Petroleum, Dehradun PIN-248005, India; E-Mail: Satya1008@hotmail.com

* Author to whom correspondence should be addressed; E-Mail: nagendra@iip.res.in; Tel.: +91-135-252-5924; Fax: +91-135-266-0203.

Academic Editors: José M. Franco and Jesús F. Arteaga

Received: 16 July 2015 / Accepted: 29 September2015 / Published: 21 October 2015

\begin{abstract}
Environmentally friendly multipurpose grease formulation has been synthesized by using Jatropha vegetable residual oil with lithium soap and multifunctional additive. The thus obtained formulation was evaluated for its tribological performance on a four-ball tribo-tester. The anti-friction and anti-wear performance characteristics were evaluated using standard test methods. The biodegradability and toxicity of the base oil was assessed. The results indicate that the synthesized residual oil grease formulation shows superior tribological performance when compared to the commercial grease. On the basis of physico-chemical characterization and tribological performance the vegetable residual oil was found to have good potential for use as biodegradable multipurpose lubricating grease. In addition, the base oils are biodegradable and non toxic.
\end{abstract}

Keywords: vegetable oil; residual oil; lithium soap; performance evaluation; biodegradable; multipurpose grease

\section{Introduction}

The worldwide trend to use more eco-friendly lubricating greases is motivated by environmental concerns [1]. Recent trends are heavily focused on price, performance as well as biodegradability and toxicity [2]. 
The biodegradability of greases essentially reflects the biodegradability of their base oils. Biodegradability is one aspect of the necessary reductions of the toxic potential of greases [3-5]. Tri glyceride based biodegradable greases are already available in the market in Germany [6]. An environmentally friendly palm-grease has been formulated from modified Refined Bleach Deodorized Palm Oil as base oil and lithium soap as thickener. Such palm-grease is dedicated for general application and or equipment working in areas where biodegradability is required such as in agriculture, forestry and coastal marine, recreation areas [7]. Total vegetable oil greases have been prepared by saponified castor oil as base oil and lithium and sodium soaps as thickener [8]. Because of their cost, synthetic ester oils are only used when the performance required cannot be achieved with mineral oils [9]. However, vegetable oils and synthetic ester based greases gives better performance besides being eco-friendly and biodegradable.

Multipurpose lubricating greases are colloid dispersive systems of base oil, thickener and additives [10]. The base oil portion of the multipurpose grease performs the actual lubrication. The thickener confers the appropriate rheological and tribological behavior to the grease. Additives improve the properties like oxidation, wear, lubricity or friction. These have a major share in the industrial applications [11]. Therefore, it is important to understand the structure and composition of the base fluid and thickener because in combination they can affect most of the physical and chemical properties of greases [12]. The performance of lubricating grease depends on the nature of its components and the microstructure achieved during its processing. Consequently, suitable structural and physical properties may be reached from a proper selection of the ingredients [13]. Multipurpose greases are not only water resistant and corrosion inhibiting but also have very good mechanical and oxidation stability as well. These greases have a major share in the industrial applications.

The residual oil which is a byproduct obtained from refining of vegetable oil or in the production of biodiesel from non edible oil, e.g., Jatrophacurcas oil besides the glycerol. The oil contains $15 \%-50 \%$ of triglyceride oil and very high free fatty acid content in the range of 50\%-85\%. The residual oil is a low cost material and has good potential for replacing the mineral base oil in the formulation of greases besides being biodegradable.

In the present paper, we have discussed the utilization of vegetable residual oils as base oils for synthesizing multipurpose lubricating greases. The performance of which is matched with the commercially available mineral oil based greases. So far no multipurpose lubricating greases having vegetable residual oil as base oil has been reported in the literature.

\section{Experimental}

\subsection{Materials}

Lithium oleate and stearate soaps were prepared in the laboratory. Jatropha vegetable and residual oil was procured from the local market. Multifunctional additive Zinc dialkyldithiophosphate was purchased from Lubrizol. 


\subsection{Preparation of Lithium Stearate/Oleate Soaps}

The dissolved Lithium acetate in ethanol was placed in a two necked round bottom flask, heated; the required quantity of oleic acid was added to it and refluxed for 6 h. The reaction product was filtered and distilled by using a vacuum. The melting point of the soap observed was between 205 and $209^{\circ} \mathrm{C}$

\subsection{Additives}

Zinc dialkyldithiophosphate (ZDDP) was used as an anti wear and anti oxidant additive. Its percentage ranges between $1 \%$ and $5 \%$. The three-dimensional nature of most grease networks can physically trap additive molecules at the metal surface to improve its lubricating properties [14].

\subsection{Apparatus}

The experimental set up consists of a hot plate as a heating source, a stirrer with adjustable speed and a grease kettle.

\subsection{Synthesis of Greases}

Lithium oleate and stearate soaps which act as thickener were prepared separately. Here the thickener makes the grease a semi solid. The base oil, soap and additives were added into the grease kettle in the amounts of $90 \%-96 \%, 3 \%-5.5 \%$ and $1 \%-5 \%$. The contents were heated to a temperature of $90-130{ }^{\circ} \mathrm{C}$ and stirred for $4-9 \mathrm{~h}$. After that, the heating was stopped, but the stirring continued until the contents were cooled to room temperature. The prepared product grease was transferred to a clean dry beaker and its weight was noted. The beaker was properly covered with an aluminum foil and it was left for overnight in order to check for its stability. If the obtained grease was separated into layers, it was discarded at this very stage otherwise it was taken as a candidate product for further study of its performance behavior.

A total of eight formulations of greases were prepared. Initially, we optimized formulations of Jatropha vegetable oil using Lithium stearate and oleate soap. Later, the formulation with Jatropha residual oil using oleate soap shows better performance.

\subsection{Mechanical and Physico-Chemical Characterization}

The tribological performance of the product was studied on four-ball machines as per ASTM-D and IP standard test methods. The dropping point, cone penetration, bio degradability, anti wear and weld load studies were conducted according to the ASTM-D-2265, ASTM-D-217, ASTM-D-5864-95, ASTM-D-2266 and IP-239 respectively. The toxicity was determined by using modified method of algal inhibition test as per the official journal of European communities. 


\subsubsection{Dropping Point}

A numeric value assigned to a grease composition representing the corrected temperature at which the first drop of material falls from the test cup and reaches the bottom of the test tube [15]. The dropping point of the grease is between 185 and $195^{\circ} \mathrm{C}$.

\subsubsection{Cone Penetration}

The National Lubricating Grease Institute classified greases according to their consistency as measured by the worked penetration. The penetration of a cone of specified dimensions, mass and finish was measured in tenths of a millimeter. These cone penetration tests not only evaluate the consistency of lubricating greases over the full range of NLGI numbers, but also evaluate the consistency of stiff greases having penetration numbers less than 85 [16]. The penetration values of samples increases with decreasing thickener content. Slight change of a parameter may result change in penetration values [17]. The NLGI consistency number alone is not sufficient for specifying the grease required by a particular application. Besides consistency, structural and mechanical stability, apparent viscosity, resistance to oxidation can be tested to determine the suitability of grease to a specific application [18].

\subsubsection{Oxidation Stability}

Oxidation stability is the ability of grease to resist a chemical union with oxygen. The Jatropha oil under normal conditions of temperature, moisture and oxygen levels will remain stable. If subjected to high temperatures in the presence of moisture and oxygen for prolonged period of time, degradation will take place. Zinc dialkyldithiophosphate (ZDDP) is found commonly in lubricating oil where it plays a role as both an antioxidant and an anti wear additive [19]. It extends the life of the lubricant grease by inhibiting oxidation, thus minimizing base oil thickening, sludging and deposits, and reducing the friction between moving parts by surface adsorption.

\subsubsection{Temperature Effects}

High temperatures accelerated oxidation or even carbonization where grease hardens or forms a crust. If the temperature of grease is lowered enough, Pump ability suffers and machinery operation may become impossible due to torque limitations and power requirements. As a guideline, the base oil's pour point is considered the low-temperature limit of grease.

\subsubsection{Pump Ability}

Pump ability is the ability of a grease to be pumped or pushed through a system. More practically, pump ability is the ease with which pressurized grease can flow through lines, nozzles and fittings of grease-dispensing systems [18]. 


\subsubsection{Water Resistance}

This test method is used to evaluate the ability of grease to adhere to a metal surface when subjected to direct water spray. The results obtained from the use of this test method suggest correlation in operations involving direct water spray impingement such as steel mill roll neck bearing service [19].

\subsubsection{Anti Wear}

The wear scar diameter was determined under the conditions including the speed of $1200 \pm 60 \mathrm{rpm}$, load of $40 \pm 2 \mathrm{kgf}$ (392 N), temperature of $75 \pm 1.7^{\circ} \mathrm{C}$ and test duration of $60 \pm 1 \mathrm{~min}$. In this method a steel ball was rotated under the load against three stationary steel balls having surface that was lubricated by grease. After completion of test, the diameter of the stationary ball was measured to determine the wear preventive characteristic of grease in sliding steel on steel application [20]. In this method we carried out two tests and their average was taken as wear scar diameter in mm.

\subsubsection{Weld Load}

The weld load was carried out at $1456 \mathrm{rpm}$ under room temperature. This standard specified procedure for the measurement of the load carrying, anti friction and anti wear property of lubricating oils and fluids by means of the four-ball machine [21]. In this method, the weld load was measured as kgf. It is a "gravitational metric" unit of force, and is equivalent to force exerted on mass of one kg in $9.806 \mathrm{~m} / \mathrm{s}^{2}$. The advantage over Newton is it avoids the use of factor $\mathrm{g}$ which is acceleration due to gravity. In kgf, where f means only force and $1 \mathrm{kgf}=9.806 \mathrm{~N}$.

\subsubsection{Biodegradability}

In this method, ultimate biodegradability of the base oil is determined. Here, biodegradability was measured by collecting the $\mathrm{CO}_{2}$ produced when the lube oil was exposed to microorganisms under controlled aerobic aquatic conditions. This value was compared with the theoretical amount of $\mathrm{CO}_{2}[22]$.

\subsection{Toxicity}

Bacterial toxicity of the base oil was determined by the modified method of Algal inhibition test. Here, instead of Algae, natural sewage Bacteria was used to determine the toxicity [23].

\section{Results and Discussion}

\subsection{Formulations with Jatropha Base Oil}

\subsubsection{Using Lithium Stearate Soap}

The compositions of the different formulations prepared are given in the Table 1 and their tribological performance is shown in the Figures 1 and 2. It is observed that in formulations 1 and 2 at low doses of soap and additives, the values of weld load are quite low. On increasing the soap content 
from 3\% to $5 \%$ in formulation 3, the weld load increased substantially from 1667.7 to $2158.2 \mathrm{~N}$. However, the values of wear scar diameter (WSD) could not be achieved to a satisfactory level. Again, on increasing the additive dose from $1 \%$ to $1.5 \%$ in formulation 4 , contrary to the normal expectation, the wear scar diameter is increased substantially to $1.643 \mathrm{~mm}$. Later, the effect of increasing soap content is also tested in formulation 5 keeping the additive dose low, a weld load of $2256.3 \mathrm{~N}$ and WSD of $0.779 \mathrm{~mm}$ are obtained. This value of weld load is considered satisfactory for multipurpose grease, however; the values of WSD are still on the higher side. So, for further improvement we moved on to try formulations with Lithium oleate soap.

Table 1. Compositional formulations of multipurpose grease with lithium stearate.

\begin{tabular}{ccccccc}
\hline $\begin{array}{c}\text { Serial } \\
\text { Number }\end{array}$ & Component & Form. 1 & Form. 2 & Form. 3 & Form. 4 & Form. 5 \\
\hline 1 & Jatropha base oil & 96 & 93.5 & 94 & 93.5 & 93.5 \\
2 & Lithium Stearate & 3 & 3 & 5 & 5 & 5.5 \\
3 & Additive & 1 & 1.5 & 1 & 1.5 & 1 \\
\hline
\end{tabular}

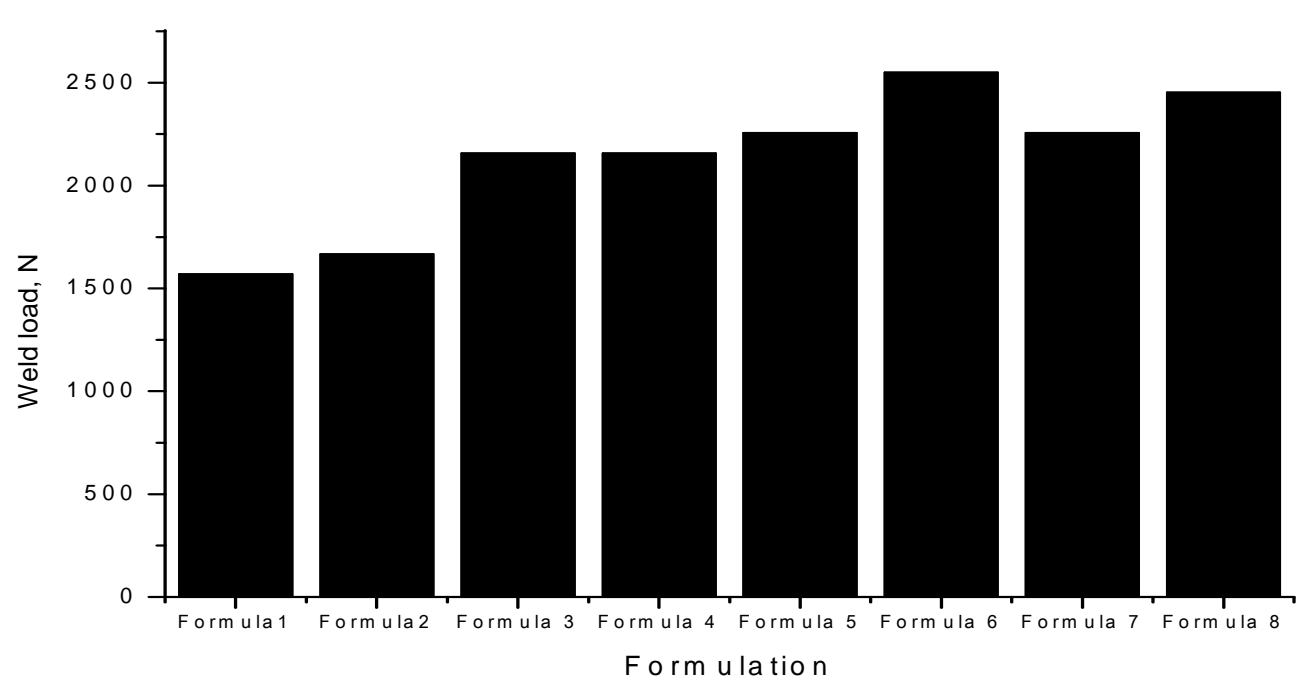

Figure 1. Weld load of formulated multipurpose grease.

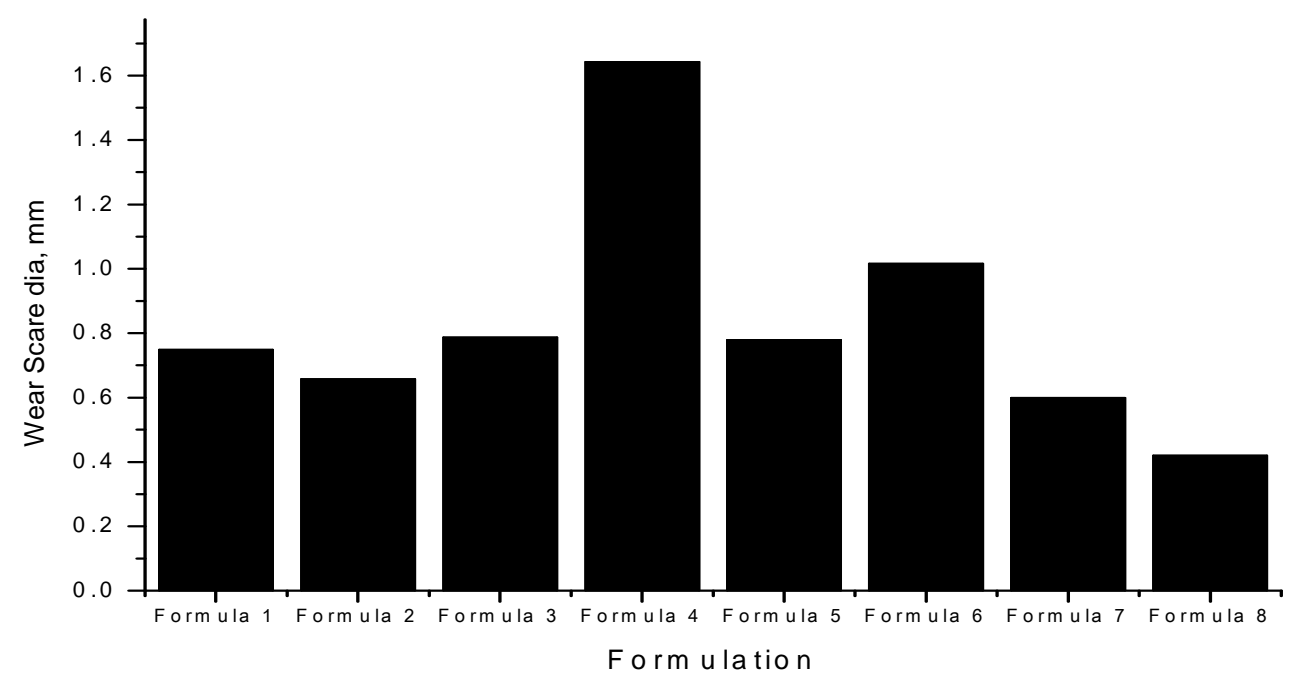

Figure 2. Wear scar diameter of formulated multipurpose grease. 


\subsubsection{Using Lithium Oleate Soap}

Various formulations prepared along with their compositions are given in the Table 2 and the results are shown in the Figures 1 and 2. It can be seen that in formulations 6 and 7 which are based on Jatropha base oil, with increase in additive dose the WSD is substantially reduced. A weld load as well as WSD of $2256.3 \mathrm{~N}$ and $0.6 \mathrm{~mm}$ respectively are satisfactory for the multipurpose grease, which is achieved with $5 \%$ soap and $5 \%$ additive (formulation 7 ). This formulation can be fine-tuned by optimizing the soap and additive doses. Keeping these results in mind we proceeded to develop further formulations with Jatropha residual oil.

Table 2. Compositional formulations of multipurpose grease with lithium oleate.

\begin{tabular}{ccccc}
\hline $\begin{array}{c}\text { Serial } \\
\text { Number }\end{array}$ & Component & Form. 6 & Form. 7 & Form. 8 \\
\hline 1 & Jatropha oil or & 93.5 & 90 & - \\
2 & Jatropha residual oil & - & - & 91 \\
3 & Lithium oleate & 5 & 5 & 4 \\
\hline
\end{tabular}

\subsection{Formulations with Jatropha Residual Oil}

Based on our results of formulations described above, we developed formulations with Jatropha residual oil as base oil using Lithium oleate soap, keeping the doses of additive and soap at around 5\% each as given in the Table 2. Finally, we arrived at formulation 8 where we obtained a weld load of 2452.5 $\mathrm{N}$ and WSD of $0.42 \mathrm{~mm}$ as shown in the Figures 1 and 2. This result is very good as far as multipurpose grease is concerned. This developed grease was NLGI grade 2 and has very good potential in the form of final product. Then we purchased multipurpose commercial grease from Indian market and studied its tribological properties to compare with our grease. Results are shown in Table 3. From this table it is observed that the tribological property of the synthesized multipurpose grease was matching with the commercial grease.

Table 3. Comparison of final residual oil formulation with commercial grease.

\begin{tabular}{ccccc}
\hline $\begin{array}{c}\text { Serial } \\
\text { Number }\end{array}$ & $\begin{array}{c}\text { Product } \\
\text { Characteristics }\end{array}$ & $\begin{array}{c}\text { Commercial } \\
\text { Sample }\end{array}$ & $\begin{array}{c}\text { Formulation } \\
\text { Developed at IIP }\end{array}$ & Test Formed \\
\hline 1. & Weld Load (N) & 1962 & 2452.5 & IP-239 \\
2. & WSD (mm) & 0.525 & 0.420 & ASTMD-2266 \\
3. & Cone penetration & NLGI-2 & NLGI-2 & ASTM D-217 \\
\hline
\end{tabular}

As a guideline, the base oil's biodegradability and toxicity is considered the biodegradability of grease. The degree of biodegradability was measured by calculating the rate of conversion of the base oil to $\mathrm{CO}_{2}$ and found that the base oil sample was degraded before recommended (28 days) period of incubation. The growth curve of the bacterial cell NS/8 indicates that there is no toxic effect of the base oil samples. The base oil was found to be non-toxic.

The developed multipurpose grease has suitable physical characteristics for the method of application and retains those characteristics during storage. It can be compatible with elastomeric seals 
and other materials associated with the parts being lubricated and maintain its structure and consistency during long periods of use. It also tolerates or resists some degree of moisture contamination without significant loss of performance.

\section{Conclusions}

A potential ecofriendly lubricating grease formulation was developed using Jatropha residual oil as base oil. The performance parameters of weld load and wear scar diameter obtained with the residual oil grease is better than that of commercial grease. Also, Residual oil, a low cost by-product has been successfully used for the development of value added product. Further studies are continuing for fine tuning of the final products.

\section{Acknowledgments}

The authors are grateful to CSIR, India for funding and would like to express sincere thanks to M.O. Garg, Director, CSIR-IIP for encouragement and support in carrying out this work and granting permission to submit paper for publication in the journal "Lubricants".

\section{Author Contributions}

The contribution of the first author Ponnekanti Nagendramma includes design and plan of the experiments, interpretation of the collected data and writing of the manuscript. The contribution of the second author Prashant Kumar includes the collection of data by performing the experiments and analysis.

\section{Conflicts of Interest}

The authors have declared no conflict of interest.

\section{References}

1. Panchal, T.; Chauhan, D.; Thomas, M.; Patel, J. Bio based grease A value added product from renewable resources. Ind. Crops Prod. 2015, 63, 48-52.

2. Kimura, H.; Onuki, Y. Properties and Applications of Synthetic Greases. J. Synth. Lubr. 2003, 20, 241-255.

3. Beret, S. Impact of base oil changes on grease performance. NLGI Spokesman 1993, 57, 192-198.

4. Goyan, R.L.; Melley, R.E.; Wissner, P.A.; Ong, W.C. Biodegradable lubricants. Lubr. Eng. 1998, 54, 10-17.

5. Voltz, M.; Yates, N.C.; Gegner, E. Biodegradability of lubricant base stocks and fully formulated products. J. Synth. Lubr. 1994, 12, 215-213.

6. Abel, W.D. Rapidly biodegradable greases for switches. In Proceedings of the 11th International Colloquim Tribology, Esslingen, Germany, 17-19 January 1998; pp. 225-236.

7. Sukirno, R.F.; Bismo, S.; Nasikin, M. Biogrease based on palm oil and lithium soap thickener: Evaluation of antiwear property. World Appl. Sci. J. 2009, 3, 401-407. 
8. Dwivedi, M.C.; Sapre, S. Total vegetable-oil based greases prepared from castor oil. J. Synth. Lubr. 2002, 19, 229-241.

9. Bower, B. Environmental Capabilities of Liquid Lubricants in Solid and Liquid Lubricants for Extreme Environments; ASLE Special Publication SP-15; ASLE: Denver, CO, USA, 1984; pp. 58-69.

10. Kuhn, E. Correlation between System Entropy and Structural Changes in Lubricating Grease. Lubricants 2015, 3, 332-345.

11. Dresel, W.; Heckler, R.-P. Chapter 16. In Lubricating Greases, Lubricants and Lubrication, 2nd ed.; Mang, T., Dresel, W., Eds.; Wiley-VCH VerlagGMbH and Co. KGaA: Weinheim, Germany, 2007; pp. 648-693.

12. Adhvaryu, A.; Erhan, S.Z.; Perez, J.M. Tribological studies of thermal and chemically modified vegetable oil for use as environmentally lubricant. Wear 2004, 257, 359-367.

13. Núñez, N.; Alfonso, J.E.M.; Valencia, C.; Sanchez, M.C.; Franco, J.M. Rheology of new green lubricating grease formulations containing cellulose pulp and its methylated derivative as thickener agents. Ind. Crops Prod. 2012, 37, 500-507.

14. Rudnick, L.R. Synthetics, Mineral Oils, and Bio-Based Lubricants: Chemistry and Technology; CRC: Press, Washington, USA, 2005; p. 468.

15. ASTM-D-2265-15. Standard Test Method for Dropping Point of Lubricating Grease over Wide Temperature Range; ASTM International: West Conshohocken, PA, USA, 2015.

16. ASTM-D-217-10. Standard Test Method for Cone Penetration of Lubricating Grease; ASTM International: West Conshohocken, PA, USA, 2015.

17. Dixena, R.; Sayanna, E.; Badoni, R. Recycled and Virgin HDPEs as bleed inhibitors and their rheological influences on lubricating greases thickened with PP and mPP. Lubricants 2014, 2, 237-248.

18. Rand, S.J. Significance of Tests for Petroleum Products, “ASTM Manual” Series; ASTM International: West Conshohocken, PA, USA, 2003; Volume 1, p. 166.

19. Barnes, A.M.; Bartle, K.D.; Vincent, R.A.T. A review of zinc dialkydithiophosphates (ZDDPS): Characterisation and role in the lubricating oil. Tribol. Int. 2001, 34, 389-395.

20. ASTM-D-2266-01. Standard Test Method for Wear Preventive Characteristics of Lubricating Grease; ASTM International: West Conshohocken, PA, USA, 2015.

21. IP-239. Determination of Extreme Pressure and Anti Wear Properties of Lubricating Fluids; Energy Institute: London, UK, 2014.

22. ASTM-D-5864-11. Standard Test Method for Determining Aerobic Aquatic Biodegradation of Lubricants or Their Components; ASTM International: West Conshohocken, PA, USA, 2015.

23. Van Miert, K. Methods for the determination of ecotoxicity, C3Algal inhibition test. Off. J. Eur. Commun. 1993, 383, 179-185.

(C) 2015 by the authors; licensee MDPI, Basel, Switzerland. This article is an open access article distributed under the terms and conditions of the Creative Commons Attribution license (http://creativecommons.org/licenses/by/4.0/). 